\title{
A Mirizzi Syndrome Revealing a Vesicular Paraganglioma: A New Observation
} \author{
Finech $\mathrm{B}^{2}$ \\ ${ }^{1}$ Department of Gastroenterology, University Hospital Med VI, Morocco \\ ${ }^{2}$ Departement of General Surgery, University Hospital Med VI, Morocco
}

Krati ${ }^{1}$, Haraki ${ }^{1 *}$, El Yazal $S^{1}$, Jiddi $S^{1}$, Lairani FZ ${ }^{1}$, Samlani $Z^{1}$, Oubaha $S^{1}$, Ryadd $A^{2}$, Bicane MA ${ }^{2}$, Louzi $A^{2}$ and

Submission: January 18 2019; Published: May 20, 2019

*Corresponding author: Haraki Imane, Department of Gastroenterology, University Hospital Med VI, Marrakesh, Morocco

\begin{abstract}
Summary
Paragangliomas are neuroendocrine tumors most often benign. The adrenal location is the most common. Very few cases of vesicular paragangliomas have been reported in the literature. Mirizzi's syndrome is a mechanical complication of vesicular lithiasis, causing the compression of the common hepatic duct. It can also lead to bilio-biliary fistulas. We report through this observation an extremely rare case associating these three entities.
\end{abstract}

Keywords: Paragangliome; Gall bladder; Mirizzi; Lithiasis

\section{Introduction}

Paragangliomas are usually benign neuroendocrine tumors that develop from paraganglion's. They are small neuro ectodermal structures derived from the neural crest and migrated parallel to the autonomic nervous system [1]. The most frequent localization is the adrenal medulla where they are called pheochromocytoma [2]. They can also be found at the carotid, retro peritoneal, nasosinus and bladder level [2,3]. Few cases of paragangliomas of the gallbladder have been sporadically reported in the literature. In addition, Mirizzi syndrome, formerly known as functional liver syndrome, is a rare complication of vesicular lithiasis related to extrinsic compression of the main bile duct by calculus embedded in the infundibulum or cystic duct. We report here an observation of a non-functional vesicular paraganglioma associated with Mirizzi syndrome.

\section{Case Report}

R.F., aged 66, having no pathological history, was referred in our department for aetiological assessment of cholestatic and permanent cutaneous mucosal jaundice appeared for 3 months. A long history of episodic liver colic is reported, aggravated two weeks before admission. On examination, we found a patient in good general condition, a BMI at $19.5 \mathrm{~kg} / \mathrm{m}^{2}$ and a WHO score at 0 , icteric without fever. Her blood pressure was normal. The biologicalassessment showed cholestasis with PAL at 400IU/land GGT at 279IU/l and accompanying cytolysis at 2.4 times normal on ALT. Leukocytosis at 12180 predominantly neutrophilic with
CRP at $24 \mathrm{mg} / \mathrm{l}$ was found. The rest of the balance was correct including renal and glycemic evaluation. Abdominal CT showed a gallbladder with multiple lithiasis, impacted at the vesicular neck, compressing the elements of the hepatic pedicle and causing extrinsic compression of the common hepatic duct. It is therefore a dilatation of the intrahepatic bile ducts. We also found a parietal thickening localized to the external part of the gallbladder opposite the segment V. The tumor markers (ACE CA 19 9) were negative. Complement with cholangiography MRI was indicated, showing the same data described above namely the lithiasic rubbing and the compression of the common hepatic duct with dilatation of the intrahepatic bile ducts carrying out the Mirizzi syndrome. The parietal thickening was diffuse and regular taking all the gall bladder.

The patient went to surgery. The gall bladder was very thickened with multiple microlithiases, with fistulization at the level of the common hepatic duct, which itself was the seat of multiple calculi. Anterograde cholecystectomy was performed with transverse choledochotomy, opening of the gallbladder and extraction of several stones. The exploration had also found a cholecysto-choledocean fistula. A Kehr drain was established after release of the common hepatic duct and the main bile duct and their washing with $0.9 \%$ saline and closure of the choledochotomy.

The anatomopathological study of the operative specimen was in favor of sub-serum tumor proliferation with uniform 
nuclei and abundant basophilic cytoplasm grouped into nests, with immunohistochemistry of synaptophysin and partial expression of chromogranin. There was no tumor cell expression to the anti-cytokeratin antibody. We did not identify foci of necrosis and the chromaffin reaction was negative. The case has therefore been reported as a type 1 paraganglioma vesicular. Posterior determination of catecholamines was normal, confirming the non-secretory nature.

The patient was declared outgoing 3 days later without complications. At 3 months of follow-up and without further treatment, the patient is still well with complete regression of symptoms and normalization of liver function.

\section{Discussion}

Paragangliomas are tumors most often benign arising from paraganglion's. They therefore develop mainly in the adrenal medulla, and less frequently in the extra-adrenal paraganglionic tissue of the sympathetic, parasympathetic and autonomic nervous system [4]. More rarely, these tumors may sit in the gallbladder, and because it is innervated by branches of the hepatic plexus surrounding the hepatic artery, the portal vein and the common hepatic duct [5]. This plexus consists of sympathetic and parasympathetic fibers derived from the vagus nerve and the celiac plexus. Thus, the presence of paraganglion's in the wall of the gallbladder is no longer a controversial subject, confirming the possibility of paraganglioma development at this level $[5,6]$.

The first case of vesicular paraganglioma was reported in 1972 by Miller et al. [1]. It was accidentally discovered during a laparotomy performed for the management of a conservative ulcer prone ulcer [1]. To our knowledge, only 9 cases have been reported sporadically since (Table 1 ). The majority was female [7-9]. The average age of onset was 52 years with extremes of 32 to 67 years. 8 out of 9 cases had symptoms pointing to gall bladder disorder. Four patients were operated for cholelithiasis and the discovery of paraganglioma was fortuitous.

Table 1: other cases of paraganglioma in the literature.

\begin{tabular}{|c|c|c|c|c|}
\hline & Year & Age/Sex & Onset & Morphology \\
\hline Miller [1] & 1972 & 67 yo/M & bleeding & Duodenal ulcer \\
\hline \multirow{2}{*}{ Wolff [5] } & \multirow{2}{*}{$1972-1973$} & 32 yo/F & gallstone & NP \\
\cline { 3 - 5 } & & 52 yo/F & gallstone & NP \\
\cline { 3 - 5 } & 2000 & 59 yo/F & gallstone & Fundus mass of the VB \\
\hline Hirano [6] & 2001 & 45 yo/F & Abdominal pain & Fundus mass of VB + diffuse thickening of the vesicular wall \\
\hline Cho [7] & 2005 & 36 yo/M & No symptom & Fundus mass of the VB \\
\hline Mehra [8] & 2006 & 50 yo/F & Abdominal pain & Cholelithiasis + dilation of VBIH \\
\hline Rodriguez [9] & 2015 & 57 yo/F & Abdominal pain & Fundus mass of the VB \\
\hline Ece et al. [3] & 2017 & 66 yo/F & Abdominal pain & Mirizzi syndrome + diffuse thickening of the vesicular wall \\
\hline Notre cas & & &
\end{tabular}

The vast majority of these paragangliomas were nonfunctional, with no excess secretion of catecholamines. Our patient had no history of personal or familial tumors, was not known hypertensive and never presented hypertensive access or flush syndrome. His blood pressure throughout his hospital stay was stable without major fluctuations and the dosage of catecholamines, even if performed after his surgery, was normal. This argues in favor of the non-functional nature of this tumor.

Histologically, paragangliomas have traits. These tumors are most often well-defined, consisting of rounded masses of cells with central nucleus, regular, fine chromatin and basophilic and granular cytoplasm. The adjoining connective tissue gives a nested (Zell Ballen) architecture to this proliferation. These nests are of variable size and shape [10]. The positivity of neuroendocrine markers (Synaptophysin, Chromogranin) is common in immunohistochemistry [11]. Paragangliomas are benign tumors most often, only $10 \%$ exhibit malignancy potential [3]. The distinction will be based more on CT rather than histology, as there are no morphological data to distinguish microscopically a benign paraganglioma from a malignant [10]. The nodular nature and the presence of confluent necrosis plaques could be considered as premonitory signs [3-12]. The presence of distant metastases or locoregional infiltration would be in favor of the malignancy.

Mirizzi syndrome was first described by KEHR in 1905, taken up by MIRIZZI in Argentina, describing complete or partial obstruction of the hepatic duct by calculus locked in cystic with acute or chronic inflammation [13]. It is a rare situation representing only 0.05 to $4 \%$ of all patients operated on for gallstones [14]. Of purely mechanical physio pathological mechanism, there are certain anatomical conditions that may favor the occurrence of this complication of vesicular lithiasis, such as a very high or very low cystico-choledochal contact located or a parallel course of the common hepatic duct and the cystic duct forming the picture in rifle barrel. it can be associated with a bilio-biliary fistula secondary to erosion of the main bile duct by landlocked calculus, imposing its closure in per-action [14]. 
Our case is the first one to include a vesicular paraganglioma and a Mirizzi syndrome complicated by a cholecysto-biliary fistula.

\section{Conclusion}

Mirizzi syndrome is a rare complication of the multi-lithiasis gall bladder. This would lead to erosion of VBP and the formation of a cholecysto-choledochal fistula. Paraganglioma is a benign tumor that is located exceptionally in the gall bladder. The association of the three makes of our observation an extremely interesting case and of an incredible scarcity.

\section{References}

1. Miller TA, Weber TR, Appelman HD (1972) Paraganglioma of the gallbladder. Arch Surg 105(4): 637-639.

2. Kliewer KE, Wen DR, Cancilla PA, Cochran AJ (1989) Paragangliomas: assessment of prognosis by histologic, immunohistochemical, and ultrastructural techniques. Hum Pathol 20(1): 29-39.

3. Ece İ, Alptekin H, Çelik ZE, Şahin M (2014) Gallbladder paraganglioma. Ulus Cerrahi Derg 31(4): 244-246.

4. Lam AK (2015) Update on Paragangliomas and Pheochromocytomas. Turk Patoloji Derg 31 Suppl 1: 105-112.

5. Wolff M (1973) Paraganglioma of the gallbladder. Arch Surg 107(3): 493

6. Hirano $T$ (2000) Paraganglioma of the gallbladder: report of a rare case. Am J Gastroenterol 95(6): 1607-1608.
7. Cho YU, Kim JY, Choi SK, Hur YS, Lee KY, et al. (2001) A case of hemorrhagic gallbladder paraganglioma causing acute cholecystitis. Yonsei Med J 42(3): 352-356.

8. Mehra S, Chung-Park M (2005) Gallbladder paraganglioma: a case report with review of the literature. Arch Pathol Lab Med 129(4): 523526.

9. Rodríguez-Merchán B, Lozoya R, Allende E, Mesa J (2006) Paraganglioma of the gallbladder. Med Clin (Barc) 127(4): 158

10. Miettinen M, McCue PA, Sarlomo-Rikala M, Rys J, Czapiewski P, et al. (2014) GATA3: a multispecific but potentially useful marker in surgical pathology: a systematic analysis of 2500 epithelial and nonepithelial tumors. Am J Surg Pathol 38(1): 13-22.

11. Weissferdt A, Kalhor N, Liu H, Rodriguez J, Fujimoto J, et al. (2014) Thymic neuroendocrine tumors (paraganglioma and carcinoid tumors): a comparative immunohistochemical study of 46 cases. Hum Pathol 45(12): 2463-2470.

12. Linnoila RI, Keiser HR, Steinberg SM, Lack EE (1990) Histopathology of benign versus malignant sympathoadrenal paraganglioma: clinicopathologic study of 120 cases including unusual histologic features. Hum Pathol 21(11): 1168-1180.

13. Chan CY, Liau KH, Ho CK, Chew SP (2003) Mirizzi syndrome: a diagnostic and operative challenge. Surgeon 1(5): 273-278.

14. Bellamlih H, Bouimetarhan L, En-nouali H, Amil T, Chouaib N, et al. (2017) Le syndrome de Mirizzi: une cause rare de l'obstruction des voies biliaires: à propos d'un cas et revue de littérature. The Pan African Medical Journal 27: 45.

\section{Your next submission with Juniper Publishers will reach you the below assets}

- Quality Editorial service

- Swift Peer Review

- Reprints availability

- E-prints Service

- Manuscript Podcast for convenient understanding

- Global attainment for your research

- Manuscript accessibility in different formats

( Pdf, E-pub, Full Text, Audio)

- Unceasing customer service

Track the below URL for one-step submission https://juniperpublishers.com/online-submission.php 